\title{
Separating wheat from Chaff: A dilemma for Intensivists in the age of Pandemics!!
}

Atul Prabhakar Kulkarni

DOI: https://doi.org/10.3329/bccj.v9i1.53048

Gordon H. Guyatt first used the term "Evidence Based Medicine"(EBM) in 19901. EBM was defined later by Sackett et al as "the conscientious, explicit, and judicious use of current best evidence in making decisions about the care of individual patients." 2

Feinstein and Horitz ${ }^{3}$ discussed the problems with the concept of EBM, whose main concern seemed to be the differences in what constituted EBM and what was practiced at the bedside.

Regardless of many other issues that were debated about the practice of EBM, it has now become a way of life. The initially envisaged problem of access to the latest literature due to poor connectivity of internet, lack of time for the busy clinicians to read the abundant literature, particularly for those practicing in the in resource poor setting is now gone.

The world has become smaller and accessible to all due to the revolutionary technology. So the only problem is time! In 1992, Haynes reported that a doctor who practiced adult internal medicine, to keep up with the latest evidence, had to read 17 articles per day, day on day every year. Of course he had to do this while looking after his patients, a task, which is impossible even now. Further agony, in this era, would be added to the task, if he has to analyze all the articles using either the critical appraisal toolbox (from the British Medical Journal) or the JAMA user guides. If you search for COVID-19 today, which I did, you get over 104,000 articles, many of which you need to read to be able to keep up with the evidence!! (Figure 1).

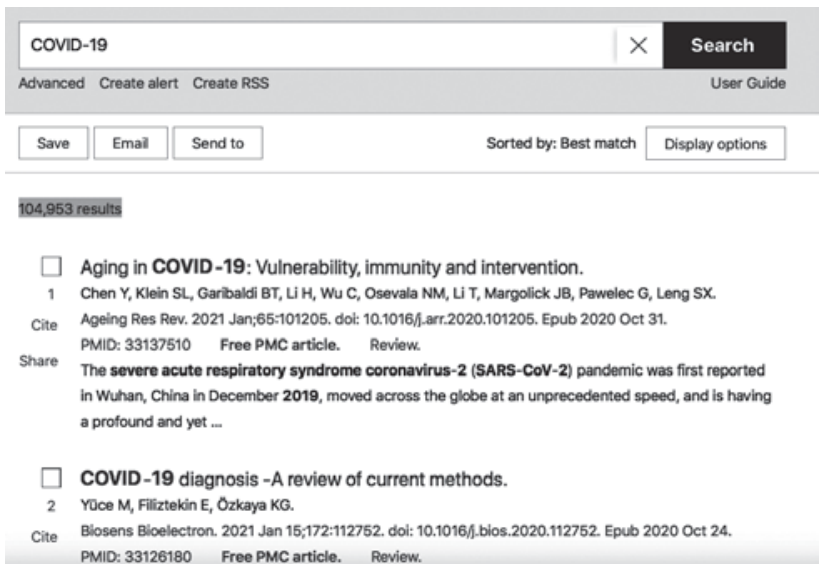

Figure 1

Normally, when a new intervention is described, it goes through a rigorous process. The intervention needs to have a pathophysiological basis and also have biological plausibility. Then animal studies are done to establish safety and efficacy of the intervention. Then begins the process of small and even larger trials. Further systematic reviews, meta-analysis and confirm the efficacy and side effects. This takes a few years, before this intervention is ultimately adapted into widespread use. The professional organizations suggest later that it be used in their guidelines and position statements and the textbooks finally incorporate it.

The task becomes even more complicated for us poor clinicians, when the psyche is intruded upon one of the (jokingly called as) "Seven alternatives to EBM". ${ }^{4}$ In this confusing story of COVID-19 pandemic appeared the classic example of the Eminence based Medicine (the marker for which is Radiance of white hair to be measured by Luminometer) combined with Vehemence based medicine (marker -Level of stridency, measured by Audiometer in decibels) by the admirably saintly looking Professor Didier Raoult from France. His group published a manuscript, in a reputable International Journal of Antimicrobial Agents paper, which described the efficacy of a combination of hydroxychloroquine (HCQ) and azithromycin. ${ }^{5}$ The end-point was soft to say the least, a reduction respiratory viral loads on day 6 post enrollment obtained by nasopharyngeal swabs, in patients with COVID-19. Surprisingly the publication was accompanied by this statement: 'Given his role as Editor in Chief of this journal, Jean Marc Rolain had no involvement in the peer-review of this article and has no access to information regarding its peer-review. Full responsibility for the peer-review process for this article was delegated to P.R. Hsueh'. There was a sort of storm when many questions were raised, not the least relating to the involvement of the editor in the manuscript written. For example, the timelines seemed impossible: "The protocol for the treatment was approved by the French National Agency for Drug Safety on March 5th 2020. The French Ethics Committee approved it on March 6th 2020. The paper states that patients were followed up until day 14, although I don't see any data from day 14 in the paper. Since the paper was submitted for publication on March 16 in the International Journal of Antimicrobial Agents, the 14-day timeline seems to be impossible. Could the authors clarify how this statement in the procedure matches the 10-day interval between ethical approval and preprint submission?" This and other fallacies led the International Society of Antimicrobial Chemotherapy (ISAC) to publish an Expression of Concern, on 4th April 2020, which stated the following: 'ISAC shares the concerns regarding the above article published recently in the International Journal of Antimicrobial Agents (IJAA). The ISAC Board believes the article does not meet the Society's expected standard, especially relating to the lack of better explanations of the 
inclusion criteria and the triage of patients to ensure patient safety.' Around, the same time, Professor Raoult led a petition appealing the French government, which was signed by over 400,000 people for making HCQ available for treatment of COVID-19.

A little later, two prominent journals; Lancet and New England Journal of Medicine, published two studies, both advocating use of HCQ and macrolides for treatment of COVID-19. ${ }^{6,7}$ Due to various reasons such as Surgisphere, American healthcare analytics company, refusing to share the patient data, etc., both journals had to retract these articles. All this while, various professional societies were also unable to determine whether to recommend HCQ and azithromycin for treatment of COVID-19. All this speculation is now put to rest by a very recent Cochrane Metaanalysis, which concluded that HCQ for people infected with SARS-COV-2 has minimal to no effect for preventing mortality. ${ }^{8}$ There is no effect on progression on severity, so that need for mechanical ventilation can be avoided. It however found that there was a 3 -fold increase in cardiovascular effects, with very few of them being serious.

A bright feature in all the doom and gloom has been the REMAP-CAP trial led by the Leeds Teaching Hospitals of NHS, UK. It is an international randomised controlled trial, looking at the efficacy of different drugs in community-acquired pneumonia in the critically ill patients. ${ }^{9}$ The first positive trial of steroids for treatment of severely ill CVOID-19 patients was published in September 2020. It used a little known, adaptive, randomised, controlled, trial design and had to be stop patient recruitment early (after 384 patients were recruited), because use of hydrocortisone showed $93 \%$ and $80 \%$ higher chance of organ support-free days within 21 days. Since then hydrocortisone has become an accepted treatment modalities in patients with severe COVID-19.

Remdesivir, though much touted for efficacy against SARS-COV-2, has not been to date shown to reduce mortality in COVID-19 patients. The first trial was published in May 2020, which showed that Remdesivir administration use led to reduction in time to improvement in the clinical condition of the patients and called for larger studies. ${ }^{10}$

Another study comparing a 5-day vs. 10-day course of Remdesivir did not find any benefit of the longer course in patients not requiring mechanical ventilation. ${ }^{11}$ A report later published of a much larger randomised controlled trial suggests that Remdesivir may be better than placebo in patients with lower respiratory tract infections, however this seems to be true only for patients who are mildly or moderately ill and the really sick patients do not benefit. ${ }^{12}$ The authors themselves suggest that remdesivir alone may not be good enough for treatment of severe COVID-19. Amidst all this, the drug was given emergency use authorization by the US-FDA, and was used in large number of patients. Many drug therapies have been suggested and fallen by wayside.

It is clear now that it pays to allow to any intervention to be studied properly, as inherent in the basic tenets of EBM. The adage "less is more" holds true even in emergency situations.
It is the nature of the intensivist to want to do something. How can I not act when the patient is deteriorating /dying comes to us as an imperative to act. We often end up in situations in pandemic as aptly put by Carley et al, when we are at a point in patient treatment, which is 'time critical and information light'. Though we are used to make decisions in such decisions due to nature of our training, we will often adopt therapies, which are cheap, and easy to adopt. A classic example is the use of awake prone position in patients with COVID-19. ${ }^{13}$ Though there are multiple observational studies, several questions persist.

The pandemic has managed to make us push the panic button, very quickly. It is important that we stick to solid, critical, cogent scientific reasoning with a calm critical mind, and not use therapies which lead many improper use of scarce resources, leading ourselves down the garden path.

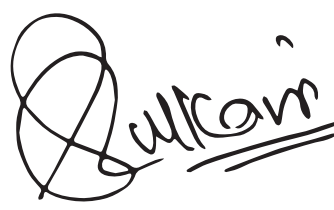

Atul Prabhakar Kulkarni

Professor \& Head, Division of Critical Care Medicine,

Department of Anaesthesiology, Critical Care \& Pain, Tata Memorial Hospital, Homi Bhabha National Institute, Dr Ernest Borges Road, Parel, Mumbai 400 012. INDIA.

e-mail:kaivalyaak@yahoo.co.in

ORCID ID 0000-0002-5172-7619

Other credentials

Editor-in-Chief, Indian Journal of Critical Care Medicine

President Asia Pacific Association of Critical Care Medicine

Past President, Indian Society of Critical Care Medicine

Past Chancellor, Indian College of Critical Care Medicine

Past President, Association of SAARC Critical Care Societies

\section{References:}

1. Guyatt GH. Evidence-Based Medicine [editorial]. ACP Journal Club 1991:A-16. (Annals of Internal Medicine; vol. 114, suppl. 2)

2. Sackett DL, Rosenberg WM, Gray JA, Haynes RB, Richardson WS. Evidence based medicine: what it is and what it isn't. BMJ. 1996; 312(7023):71-2. doi: 10.1136/bmj.312.7023.71.

3. Feinstein AR, Horwitz RI. Problems in the "evidence" of "evidence-based medicine". Am J Med. 1997; 103(6):529-35. doi: 10.1016/s0002-9343(97)00244-1. 
4. Isaacs D, Fitzgerald D. Seven alternatives to evidence based medicine. BMJ. 1999; 319(7225):1618. doi: $10.1136 / \mathrm{bmj} .319 .7225 .1618$

5. Gautret P, Lagier JC, Parola P, Hoang VT, Meddeb L, Mailhe M, Doudier B, et al. Hydroxychloroquine and azithromycin as a treatment of COVID-19: results of an open-label non-randomized clinical trial. Int J Antimicrob Agents. 2020; 56(1):105949. doi: 10.1016/j.ijantimicag.2020.105949.

6. Mehra MR, Desai SS, Ruschitzka F, Patel AN. RETRACTED: Hydroxychloroquine or chloroquine with or without a macrolide for treatment of COVID-19: a multinational registry analysis. Lancet. 2020 May 22:S0140-6736(20)31180-6. doi 10.1016/S0140-6736(20)31180-6. Retraction in: Lancet. 2020 Jun 5.

7. Mehra MR, Desai SS, Kuy S, Henry TD, Patel AN. Cardiovascular Disease, Drug Therapy, and Mortality in Covid-19. N Engl J Med. 2020 Jun 18;382(25):e102. doi: 10.1056/NEJMoa2007621. Epub 2020 May 1. Retraction in: N Engl J Med. 2020 Jun 4;: PMID: 32356626; PMCID: PMC7206931.

8. Singh B, Ryan H, Kredo T, Chaplin M, Fletcher T. Chloroquine or hydroxychloroquine for prevention and treatment of COVID-19. Cochrane Database Syst Rev. 2021 Feb 12;2:CD013587. doi: 10.1002/14651858.CD013587.pub2.

9. Angus DC, Derde L, Al-Beidh F, Annane D, Arabi Y, Beane A, et al. Effect of Hydrocortisone on Mortality and Organ Support in Patients With Severe COVID-19: The REMAP-CAP COVID-19 Corticosteroid Domain Randomized Clinical Trial. JAMA. 2020; 324(13): 1317-1329. doi: 10.1001/jama.2020.17022.
10. Wang Y, Zhang D, Du G, Du R, Zhao J, Jin Y, et al. Remdesivir in adults with severe COVID-19: a randomised, double-blind, placebo-controlled, multicentre trial. Lancet. 2020; 395(10236):1569-1578. doi: 10.1016/S0140-6736(20)31022-9.

11. Goldman JD, Lye DCB, Hui DS, Marks KM, Bruno R, Montejano $\mathrm{R}$, et al. Remdesivir for 5 or 10 Days in Patients with Severe Covid-19. N Engl J Med. 2020; 383(19):1827-1837. doi: 10.1056/NEJMoa2015301.

12. Beigel JH, Tomashek KM, Dodd LE, Mehta AK, Zingman BS, Kalil AC; ACTT-1 Study Group Members. Remdesivir for the Treatment of Covid-19 - Final Report. N Engl J Med. 2020; 383(19):1813-1826. doi: 10.1056/NEJMoa2007764.

13. Caputo ND, Strayer RJ, Levitan R. Early Self-Proning in Awake, Non-intubated Patients in the Emergency Department: A Single ED's Experience During the COVID-19 Pandemic. Acad Emerg Med. 2020; 27(5):375-378. doi: 10.1111/acem.13994.

14. Carley S, Horner D, Body R, Mackway-Jones K. Evidence-based medicine and COVID-19: what to believe and when to change. Emerg Med J. 2020; 37(9): 572-575. doi 10.1136/emermed-2020-210098. 